\title{
Gender Stereotypes in Children's Play, Pro-social and Aggressive Behavior in the Kindergarten Class: The Kindergarten Teachers' Stance
}

\author{
Evangelia Saramourtsi ${ }^{1}$, Makrina Zafiri ${ }^{2,}$, Vassiliki Pliogou $^{3}$ \\ ${ }^{1}$ Department of Early Childhood Education, School of Education, Aristotle University of Thessaloniki, Greece \\ ${ }^{2}$ Foreign Language Office, Aristotle University of Thessaloniki, Greece \\ ${ }^{3}$ Department of Early Childhood Education, School of Humanities and Social Sciences, University of Western Macedonia, Greece
}

Received October 8, 2020; Revised November 23, 2020; Accepted December 13, 2020

\section{Cite This Paper in the following Citation Styles}

(a): [1] Evangelia Saramourtsi, Makrina Zafiri, Vassiliki Pliogou , "Gender Stereotypes in Children's Play, Pro-social and Aggressive Behavior in the Kindergarten Class: The Kindergarten Teachers' Stance," Universal Journal of Educational Research, Vol. 8, No. 12A, pp. 7992-8009, 2020. DOI: 10.13189/ujer.2020.082587.

(b): Evangelia Saramourtsi, Makrina Zafiri, Vassiliki Pliogou (2020). Gender Stereotypes in Children's Play, Pro-social and Aggressive Behavior in the Kindergarten Class: The Kindergarten Teachers' Stance. Universal Journal of Educational Research, 8(12A), 7992-8009. DOI: 10.13189/ujer.2020.082587.

Copyright $@ 2020$ by authors, all rights reserved. Authors agree that this article remains permanently open access under the terms of the Creative Commons Attribution License 4.0 International License

\begin{abstract}
This research paper focuses on the issue of gender stereotypes and, more particularly, on the way in which kindergarten students choose the toys and games/activities that they play and the manifestation of specific behaviors which they express in the kindergarten class. The research questions attempted to answer to the correlation of gender stereotypes and the student's choices of toys and games/activities, and the manifestation of pro-social and aggressive behaviors in students, as well as the teachers' views on the influence which gender stereotypes exert on students and the way teachers attempt to solve related problems. As part of the research, semi-structured interviews with ten teachers who worked in Greek kindergarten schools were conducted, in order to explore their views and attitudes on the issues stated above. The results of this research show that kindergarten teachers spot differences in kindergarten students' choices of toys and games/activities, as well as in the behavior between boys and girls. The responses of the kindergarten teachers show that they do not all agree that the aforementioned differences are due to gender stereotypes. The results also show that kindergarten teachers are aware of the ways in which gender stereotypes affect kindergarten students in the family and the school environment. Kindergarten teachers also stated that they know how to deal with gender stereotype problems which may arise in their classes.
\end{abstract}

Keywords Gender, Gender Stereotypes, Kindergarten, Play, Behavior

\section{Introduction}

Despite the general progress in the field of gender equality, gender stereotypes still continue to bear roots in people's perceptions at a global scale. The educational field does not remain untouched by this phenomenon, as teachers tend to consciously or unconsciously treat students according to their gender, from the way they sit in the class to the expectations for their academic performance [1]. Gender stereotypes influence student's psyche from an early age, and this seems to continue throughout their lives, shaping their confidence, their sense of competence, and their aspirations for the future [2]. Through the various stages of age, which students go through, the pre-school age is inarguably the most important stage for the development of their sense of self and of their gender identity. Students' choices of toys and games, as well as the pro-social and aggressive behaviors which they display in kindergarten, are issues that have been studied by many researchers (see [3, 4]). But the kindergarten teachers' stance on the aforementioned 
issues, especially the issue of gender and their choice of toys and games as well as their pro-social and aggressive behaviors, have not been the subject of many studies in Greece.

The purpose of this research is to explore the views of practicing kindergarten teachers on the ways in which gender stereotypes are seen in the daily life of a kindergarten class, as well as to investigate the teachers' attitudes on the influence that gender stereotypes exert on very young students. The research focuses on the choice of toys and games/outdoor activities and on the manifestation of pro-social and aggressive behaviors that students engage in, while also emphasizing on the individual beliefs and experiences of kindergarten teachers on the way in which gender stereotypes affect students in an educational setting, but also in their everyday lives. The research questions which are posed are as follows:

- What are the kindergarten teachers' perspectives on girls' and boys' choices of toys in the class?

- What are the kindergarten teachers' perspectives on girls' and boys' choices of games/outdoor activities during recess?

- What are the kindergarten teachers' perspectives on girls' and boys' pro-social behavior at school?

- What are the kindergarten teachers' perspectives on girls' and boys' aggressive behavior at school?

- How do kindergarten teachers evaluate the influence of gender stereotypes on students?

- How do kindergarten teachers deal with problems related to gender stereotypes in their class?

\subsection{Gender and Identity}

The broader concept of "sex" includes two categories: the biological and the social sex. Unlike the biological sex, which is genetically predetermined, the social sex (most commonly known as "gender") concerns the attitudes, behaviors, and characteristics that a culture associates with a person's biological sex, making it a cultural and social construction [5]. Gender is related to an individual's perception of himself/herself and his/her position in the context of social interaction. During childhood, these perceptions are first formed and influenced by the direct actors of socialization (e.g. family, school) and then by indirect actors (e.g. media, religion, cultural norms). Directly related to gender is the concept of gender identity, which concerns the perception that people have of themselves as males or females, and it is established from a very young age depending on the stimuli that the child receives from his immediate environment [6]. Over the years, various theories have been developed on how gender identity is structured, the most important of which are Köhlberg's theory of cognitive gender development (1966), Bandura's theory of social learning (1967) and Bem's gender schema theory (1981).

\subsection{Gender Stereotypes}

Gender stereotypes are defined as the perceptions of a culture or society about the traits that individuals are expected to display based on their gender. These traits include activities, interests, skills, and occupation [7]. Internalizing gender stereotypes is a key aspect of understanding gender in childhood. From a young age, children/students perceive the various stereotypes concerning their gender, through their interaction with their parents, teachers and peers [8]. In the family context, parents often point out to their children what they should or should not do depending on their gender, through daily communication and interaction with them [9]. In particular, it is found that girls and boys receive different treatment in areas such as verbal interaction, acceptable behaviors and expectations concerning their academic performance [10].

In the school context, teachers do not usually recognize the problem of gender stereotypes as particularly important [11]. Research, however, shows that girls are seen, by teachers, as more receptive and willing to try things in class, while boys are seen as more disruptive but with innate abilities [12]. Although students come to school carrying certain stereotypes, the teachers' beliefs and pedagogical philosophy can substantially influence the position of gender stereotypes in the class [13].

\subsection{Play}

Seeing that toys are cultural products; they are undoubtedly related to gender stereotypes [14]. Toys addressed to girls are characterized by stereotypes such as the need to provide care (e.g.: baby dolls, kitchenware) and the focus on external appearance (e.g., makeup kits). Toys addressed to boys are characterized by stereotypes such as an interest in action (e.g., superhero dolls, weapons), sports (e.g., soccer equipment), construction (e.g., blocks) and vehicles (e.g., cars). The provision of toys with specific characteristics, therefore, significantly affect young students' formation of gender identity [15]. In kindergarten, the play corners are often "constructed" according to gender, with "girls' toys" placed in the dollhouse corner and "boys' toys" placed in the building material corner. These two play corners are observed in most kindergartens and are mostly used by girls and boys respectively [16].

Gender stereotypes are also observed in the games/activities that take place during recess. In kindergarten, boys prefer active play or play with different materials, while girls prefer the playground equipment and symbolic play. Kindergarten teachers often provide different materials to students, by giving balls to boys which are intended for intense games, and by giving girls hula-hoops, ribbons and ropes for quieter play [17]. It is also found that boys participate more often in rough-and-tumble play, which involves physical contact but has no violent intentions [18]. 


\subsection{Behavior}

Regarding the manifestation of pro-social behaviors, it is argued that girls prevail over boys, due to their higher level of empathy [19]. Other researchers, however, argue that boys also exhibit pro-social behaviors but in a different way, which makes the above findings contradictory. The different pro-social behaviors which have been observed between boys and girls depend on the learning and evaluation of these behaviors from the student's environment [20]. Girls are expected to express their pro-sociality more in the form of care and empathy, while boys express theirs more in the form of defence and assertation. So, the difference does not lie in the general tendency of girls and boys for pro-social behaviors, but rather in the way they express this tendency [20].

Regarding the manifestation of aggressive behaviors, the differences between boys and girls are again qualitative. Boys appear to express physical aggression more, while girls express relational aggression more [21]. This fact is mainly attributed to the different treatment of boys and girls by the family environment. Seeing as men are considered to be more dynamic and assertive, parents are more likely to pass on to their boys that aggression is something which is considered tolerable. On the other hand, as girls are considered sweet and calm, they are expected to find more indirect ways to express their aggressive tendencies [22]. It is also found that teachers pay more attention to the occurrence of aggressive behavior by boys, while the aggressive behavior of girls may go unnoticed. It is important, however, to pay attention to all forms of aggressive behavior displayed by students, in order for kindergarten teachers to intervene early enough [23].

\section{Research Method}

The present study utilized the qualitative approach, as it was deemed more appropriate in order to investigate this specific issue. The sampling method used to approach the participants was a combination of typical case sampling and snowball sampling. In a typical case sampling, the researcher selects participants who are considered "typical" in terms of characteristics that are important to the researcher [24]. For this research, kindergarten teachers working in a public or private kindergarten with at least one year of work experience were approached. After approaching the first individuals, the snowball sampling method was used by utilizing the individuals' social network to reach other members of the same population, in this case kindergarten teachers [24].

For the data collection, semi-structured interviews were conducted with ten female kindergarten teachers, who worked in public or private Greek kindergartens. An interview guide was constructed and used in the interviews, which consisted of the following three sections of questions (excluding the demographic questions): 1) questions on play, 2) questions on behaviors, 3) questions on the kindergarten teachers' views and stance on gender stereotypes. Even though an attempt was made to include male kindergarten teachers in the research, due to the vast majority of women in the field of kindergarten education, the participants were all women. The participants' profiles are presented below, as they emerged from their answers to the demographic questions of the interview:

- $\quad$ Eight (8) participants had a degree in kindergarten education as their first degree, while two (2) participants had it as their second degree.

- Six (6) participants had completed postgraduate studies in the field of education, while four (4) participants had not completed postgraduate studies.

- $\quad$ Two (2) participants had completed doctoral studies in the field of education, while eight (8) participants had not completed doctoral studies.

- $\quad$ Nine (9) participants had attended seminars with an educational content, while one (1) participant had not.

- The participants' years of work experience ranged from 1-33, as follows: 1 year - one (1) participant, 3 years - one (1) participant, 8 years - one (1) participant, 9 years - one (1) participant, 14 years three (3) participants, 20 years - one (1) participant, 22 years - one (1) participant, 33 years - one (1) participant.

- $\quad$ Nine (9) participants worked in a public kindergarten, while one (1) participant worked in a private kindergarten.

- Eight (8) participants had approximately equal numbers of boys and girls in their class, while one (1) participant had an overwhelmingly larger number of boys in her class (11 boys and 4 girls) and one (1) participant had an overwhelmingly larger number of girls in her class (12 girls and 6 boys).

In order to analyze the data obtained from the interviews, the method of content analysis (qualitative and quantitative) was applied, which guaranteed objectivity and validity. As a research method, content analysis is systematic, compatible with other methods and can detect trends. It can also manage a large amount of data, without affecting the behavior of informants [25]. The aim of content analysis is to lead the researcher to verifiable and valid conclusions that emerge from written texts, images, films, etc. and that relate to the context in which they are used [26]. In the analysis that follows, the data has been divided into the three sections of question of the interview guide and the kindergarten teachers' answers are presented in the form of figures/graphs, accompanied by indicative comments of the teachers. In order to maintain the kindergarten teachers' anonymity in this research, the real name of each teacher is replaced by the letter " $\mathrm{N}$ " and a number when mentioned in the analysis of the data. 


\section{Analysis of Data}

- Choices of toys and games/activities

The first question of this section was about the toys that girls usually choose in the class. The following figure presents the various options listed:

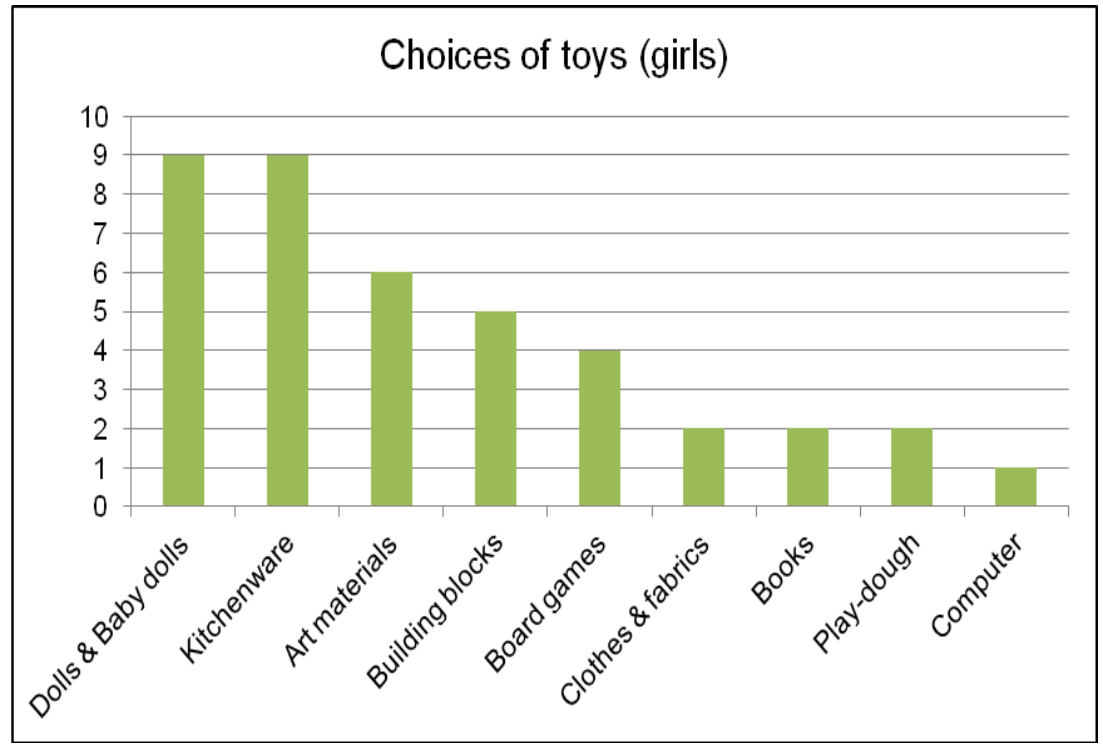

Figure 1. Girls' choices of toys in the classroom

Three participants pointed out that there is a system of continuous rotation of toys in their class, in the play corners, or students who are allowed to play in them, which results in all students choosing all toys eventually (e.g., N4: «...this school has a system for students to play where the kindergarten teacher constantly alternates them, so that everyone plays with almost everything»). The other seven participants (who did not mention this system) would give the students access to all the toys in the class, therefore reporting the above choices in their observations.

The second question was about the teachers' evaluation of the girls' choices. The following figure presents the teachers' opinions:

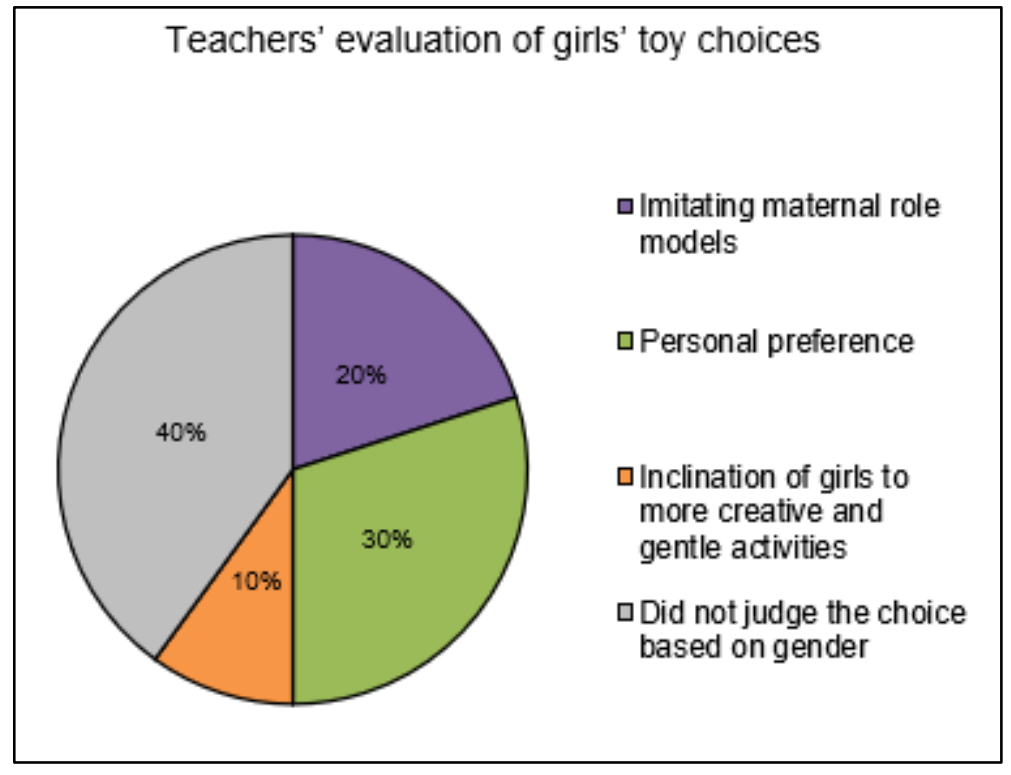

Figure 2. Teachers' evaluation of girls' toy choices in the classroom

Some indicative answers are those of participants N1: «they behave a little like their mother [...] what she does at home, her chores, the baby she may have to feed», N10: «each student follows his/her own desires, his/her own needs 
for play», and N6: «girls want more creative and more calm things to do, without much intensity and movement...they try to express their emotions more in this way, to express themselves».

The third question was about the toys that boys usually choose in the class. The following figure presents the various options listed:

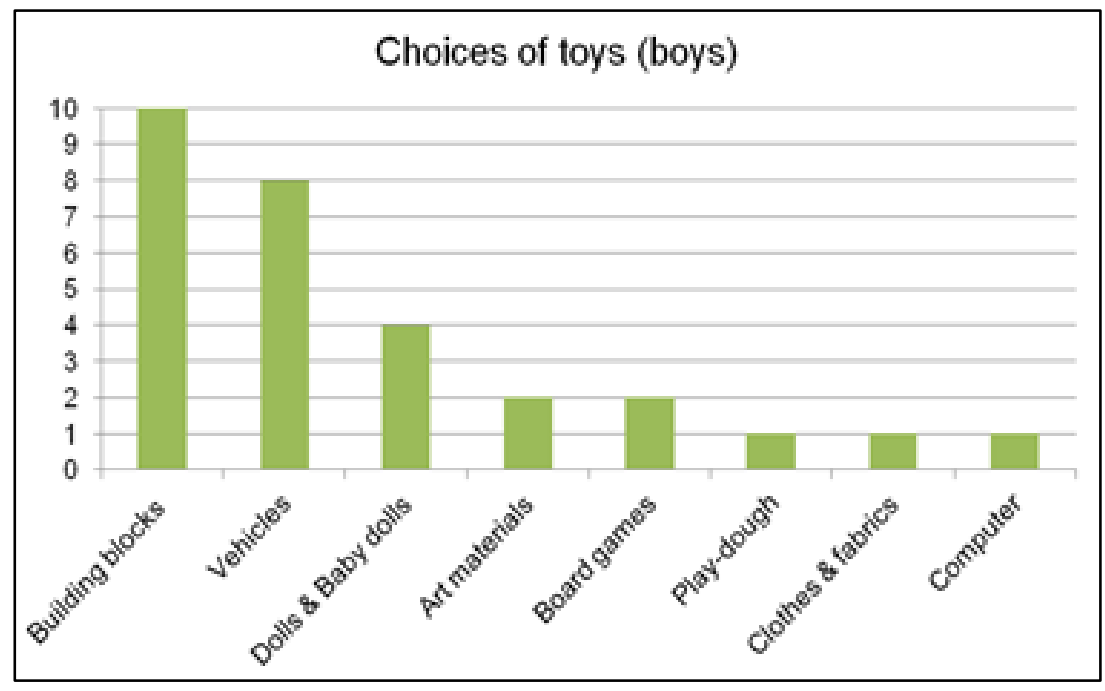

Figure 3. Boys' choice of toys in the classroom

As in the first question concerning the girls' choices, three participants reported a system of toy rotation in the play corners, while seven participants gave the students access to all the toys in the class, therefore reporting the above choices in their observations.

The fourth question was about the teachers' evaluation of the boys' choices. The following figure presents the teachers' opinions:

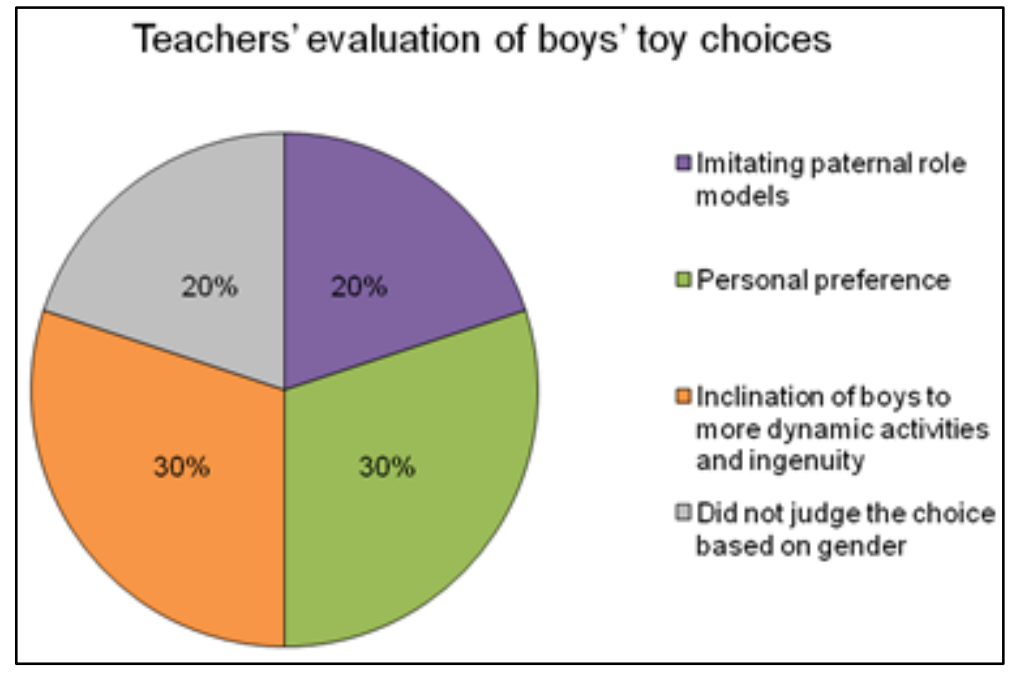

Figure 4. Teachers' evaluation of boys' toy choices in the classroom

Some indicative answers are those of participants N9: «[...] it has to do with the dad, if he usually deals with medical or engineering tools», N8: «[...] I think that it is very familiar to them, because they also have it [the toy] at home», and $\mathrm{N} 1:$ «[...] boys' minds, by nature, are a little more complex, in terms of the fact that they like to engage in constructions and generally complex activities».

The fifth question was about the games/activities that girls usually choose at recess. The following figure presents the various options listed: 


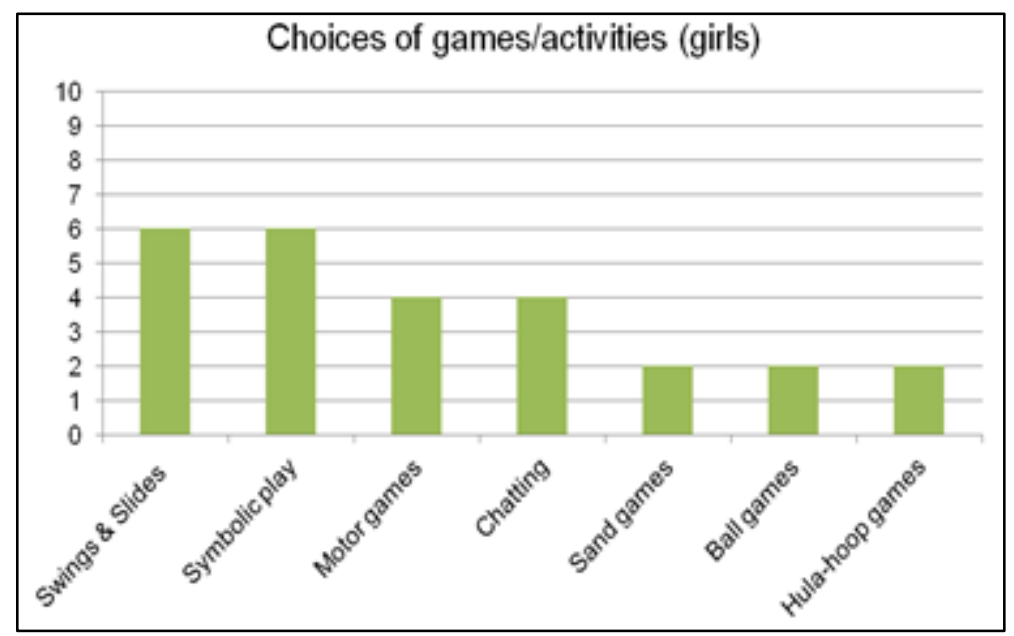

Figure 5. Girls' choices of games/activities at recess

The sixth question was about the teachers' evaluation of the girls' choices. The following figure presents the teachers' opinions:

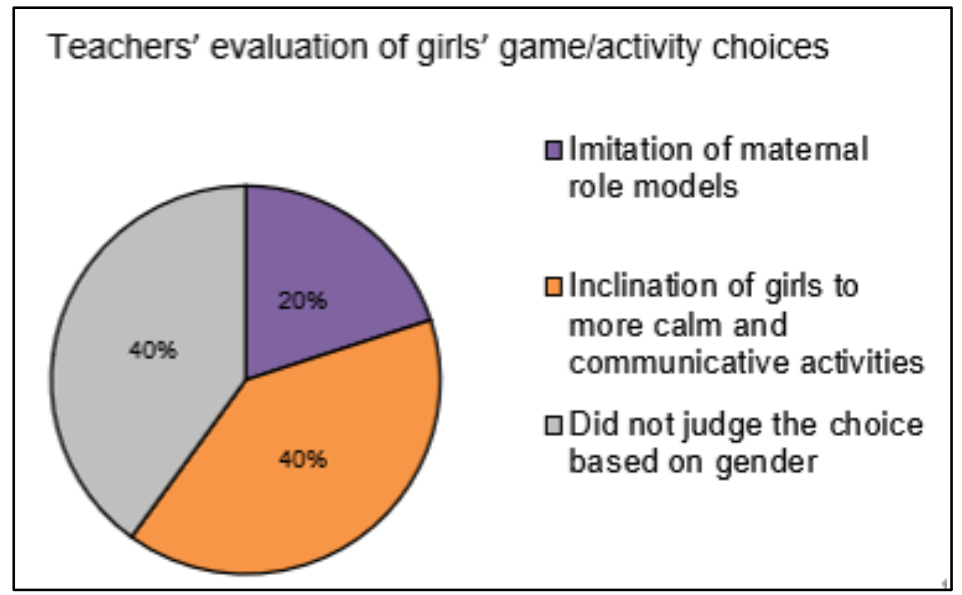

Figure 6. Teachers' evaluation of girls' games/activities choices at recess

Some indicative answers are those of participants N1: «[...] it is the type of role model that girls see at home» and N8: «girls like to swing on the swing, or to do something a little calmer».

The seventh question was about the games/activities that boys usually choose at recess. The following figure presents the various options listed:

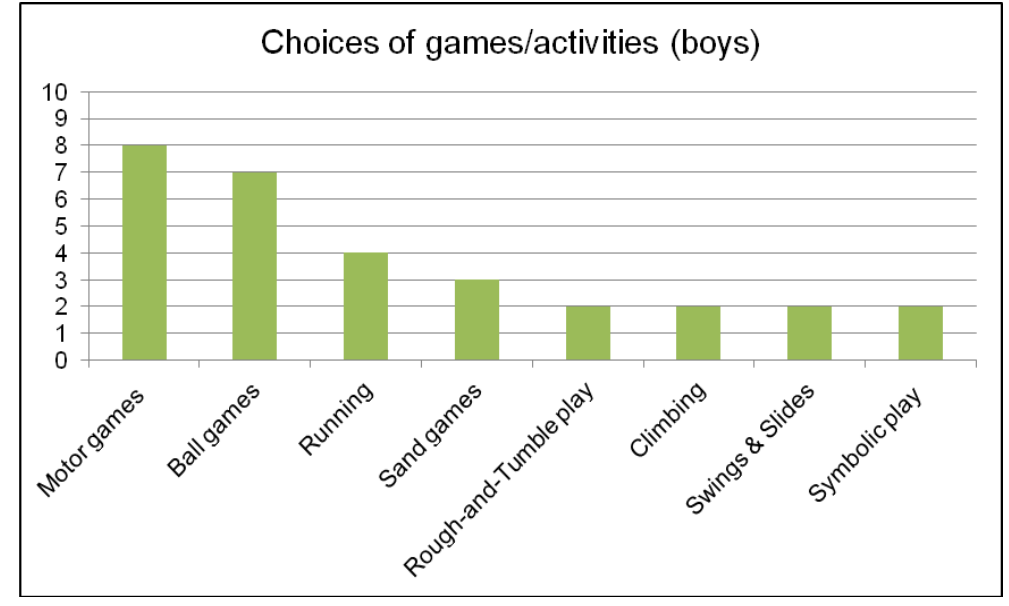

Figure 7. Boys' choices of games/activities at recess 
The eighth question was about the teachers' evaluation of the boys' choices. The following figure presents the teachers' opinions:

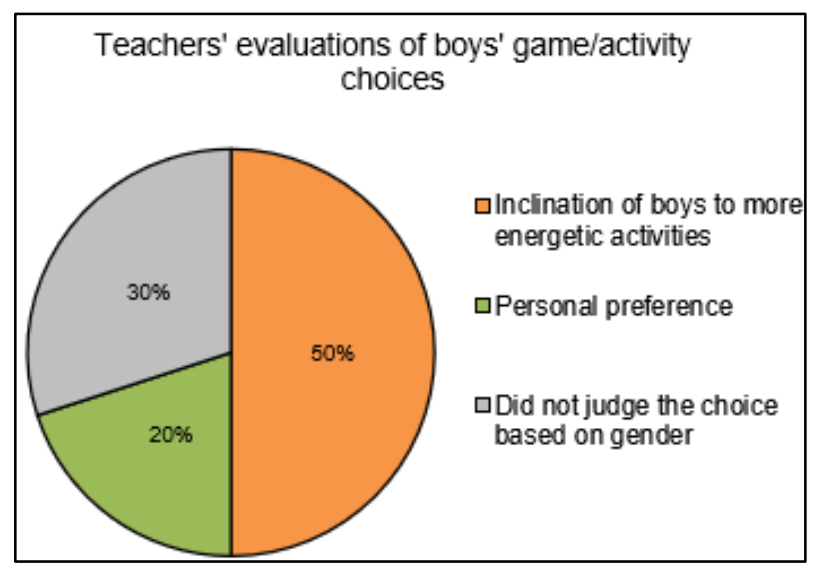

Figure 8. Teachers' evaluation of boys' games/activities choices at recess

Some indicative answers are those of participants N1: «[...] they are a little more inventive and more active and they are always looking for more dangerous things to do like to climb or play with sticks» and N7: «students who are more active and energetic can be both boys and girls. I think it has more to do with their character than with their gender».

\section{- Pro-social and aggressive behaviors}

In terms of pro-social behavior, the four parameters considered were sharing, helping, cooperating, and defending. The questions attempted to pin-point the possible differences between boys and girls in the manifestation of each parameter, while also attempting to present a possible case of gender-incompatibility of pro-social behavior.

Regarding students' sharing behavior, only one participant noticed a difference (N6: «girls are kinder. If they want something, they ask for it in a nicer way, calmer, without too much noise»). Nine participants reported no difference. Those participants' opinions are presented in the following figure:

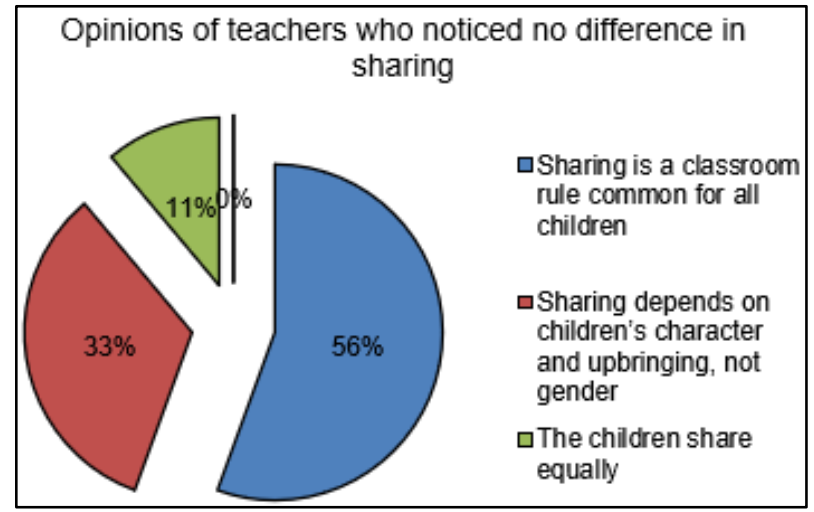

Figure 9. Opinions of teachers who did not notice a difference in sharing
Some indicative answers are those of participants N7: «the difference depends on the extent to which they follow the rules, because this one [sharing] is one of the rules», N2: «it has nothing to do with whether it's a girl or a boy, but with how they have been taught from home», and N9: «there is a balance there, because both boys and girls in this class share the same toys [...]».

Regarding students' helping behavior, four participants reported noticing a difference. Those participants' opinions are presented in the following figure:

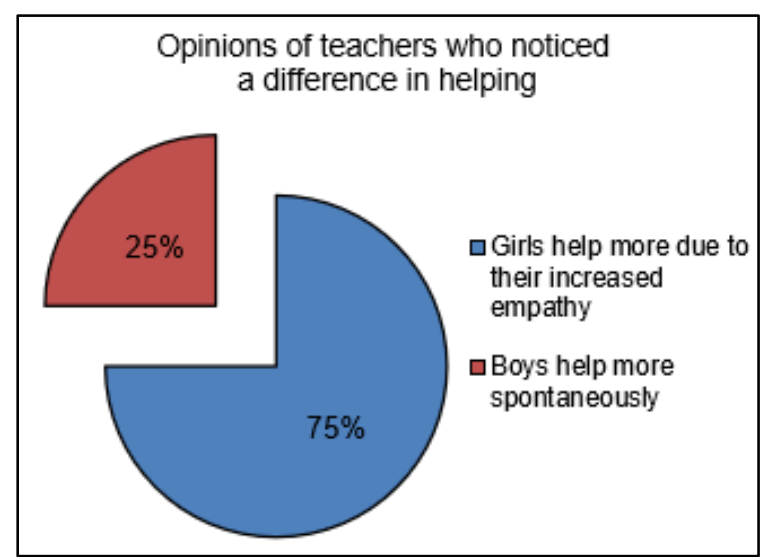

Figure 10. Opinions of teachers who noticed a difference in helping

Some indicative answers are those of participants N1:

" [...] girls show more understanding of others' pain and feel sorrier for their friends, they will approach others and will give their help more easily» and N2: «I think girls will take more into account whether or not the other student is their friend, boys are more spontaneous there». The other six participants reported no difference. Those participants' opinions are presented in the following figure:

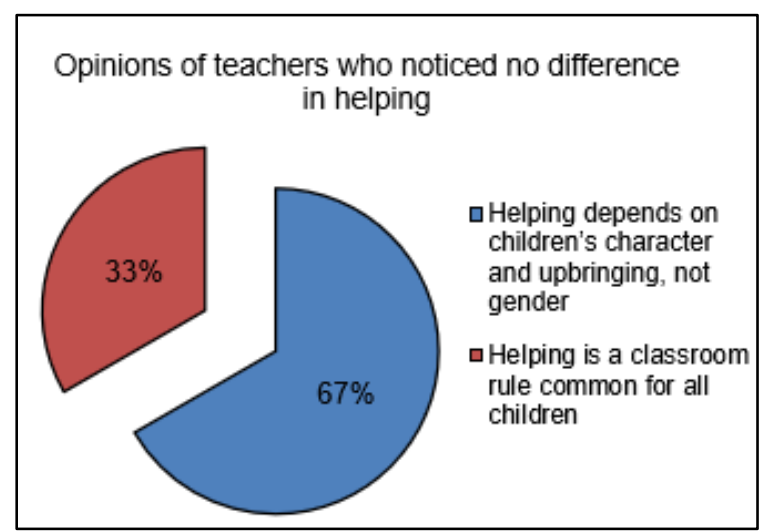

Figure 11. Opinions of teachers who did not notice a difference in helping

Some indicative answers are those of participants N3: «it is a matter of character, how a student generally behaves» and N8: «the matter of 'helping each other' was something that I personally have worked hard for in my class since the beginning of the year [...] I have tried to 
inspire students to help each other, without separating boys from girls».

Regarding students' cooperative behavior, four participants reported noticing a difference. Those participants' opinions are presented in the following figure:

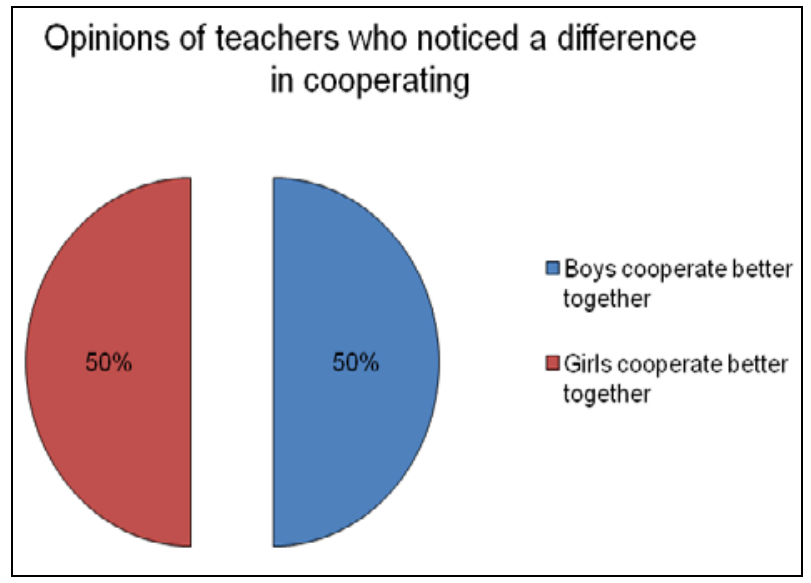

Figure 12. Opinions of teachers who noticed a difference in cooperating

Some indicative answers are those of participants N9: «boys usually cooperate more easily with each other» and N4: « [...] I think girls are a little more mature, they will communicate more easily in a game or a given assignment». The other six participants reported no difference. Those participants' opinions are presented in the following figure:

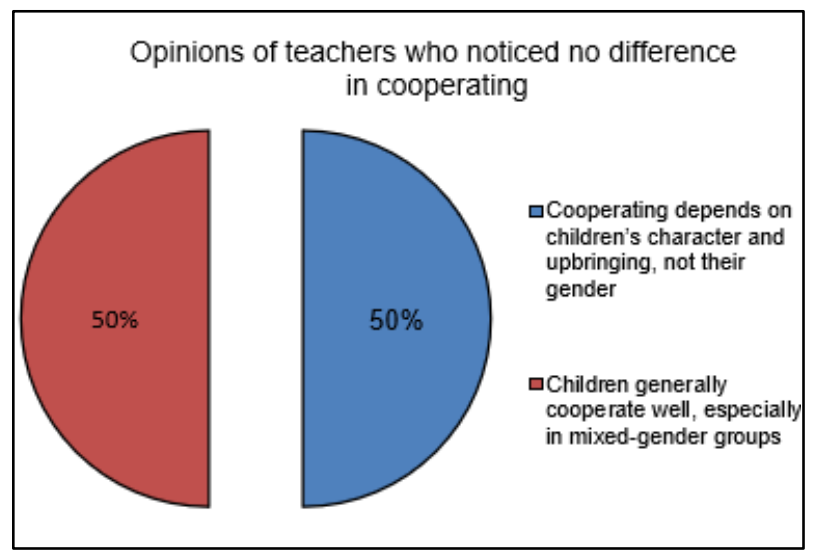

Figure 13. Opinions of teachers who did not notice a difference in cooperating

Some indicative answers are those of participants N10: «I have seen specific behaviors from girls, in which jealousy seems to surface, but this also seems to appear in boys who sometimes quarrel, so I cannot identify these behaviors as gender specific» and N2: «if the groups are mixed, it goes smoother, as if both genders are 'heard' more and a better cooperation surfaces, than if they were only boys or only girls».

Regarding students' defensive behavior, five participants reported noticing a difference. Those participants' opinions are presented in the following figure:

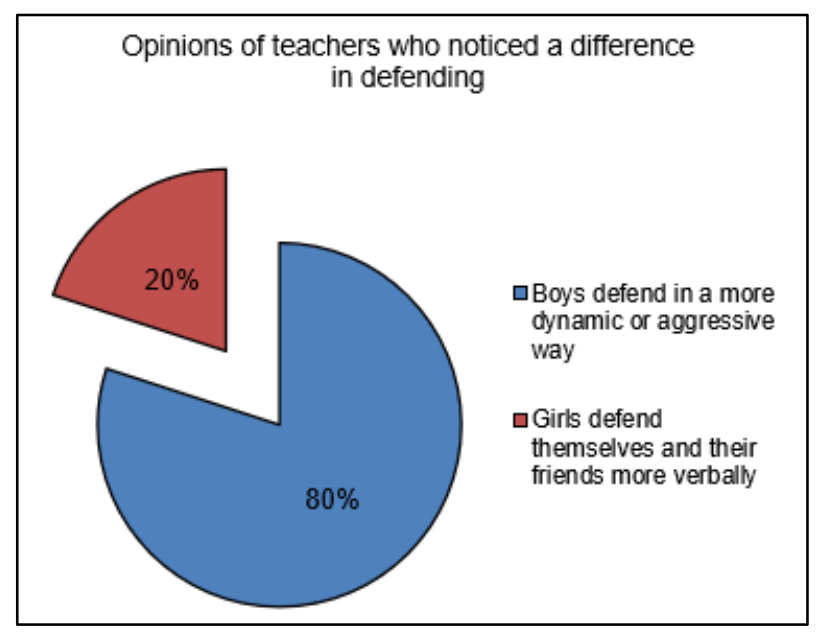

Figure 14. Opinions of teachers who noticed a difference in defending

Some indicative answers are those of participants N1: «I think boys are more aggressive, that is, they will display more physical forms of aggression or voice a swear word» and N6: "girls might start a dialogue, saying things like 'why did you do that?' and 'you should not have done that' and 'now you will lose your friend', in a softer and calmer tone». The other five participants reported no difference. Those participants' opinions are presented in the following figure:

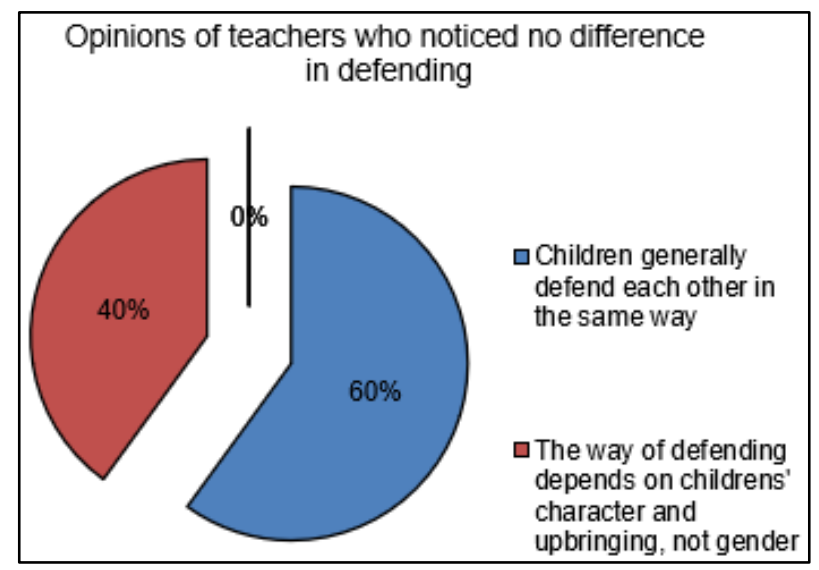

Figure 15. Opinions of teachers who did not notice a difference in defending

Some indicative answers are those of participants N8: «they use only words, not action, I would say that for both boys and girls» and N3: «usually both genders will defend their friends, they just do it in another way, depending on their character».

Regarding cases of gender-incompatible manifestation of pro-social behavior, five participants reported the same case: a boy who showed great empathy or generally presented a mild behavior (e.g., N7: «I have a couple of boys who I would say behave 'like girls', in the sense that they are very kind, very willing to help, very sensitive»). 
All five participants commented on the child's character or upbringing as the cause for such behavior (e.g. N1: «[...] if at home they speak in a certain way or follow certain parenting styles, it makes sense that the child will follow in their footsteps»). Five participants reported no case.

In terms of aggressive behavior, three forms were considered: physical, verbal and relational aggression. The questions concerned the possible differences between boys and girls in the manifestation of each, as well as the possible case of gender-incompatibility of aggressive behavior.

Regarding physical aggression, nine participants reported a difference. Those participants' opinions are presented in the following figure:

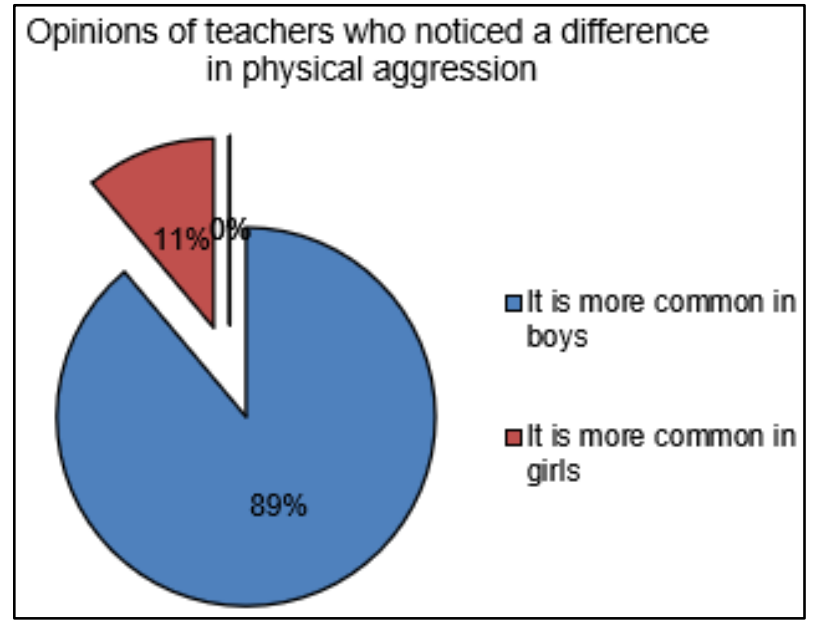

Figure 16. Opinions of teachers who noticed a difference in physical aggression

Some indicative answers are those of participants N4: «they solve many things using physical force, like pushing, hitting, kicking» and N8: «mostly girls push». One participant stated that she did not notice any difference, arguing that expressing physical aggression depends on the students' characters and their upbringing, not their gender.

Regarding verbal aggression, six participants reported a difference. Those participants' opinions are presented in the following figure:

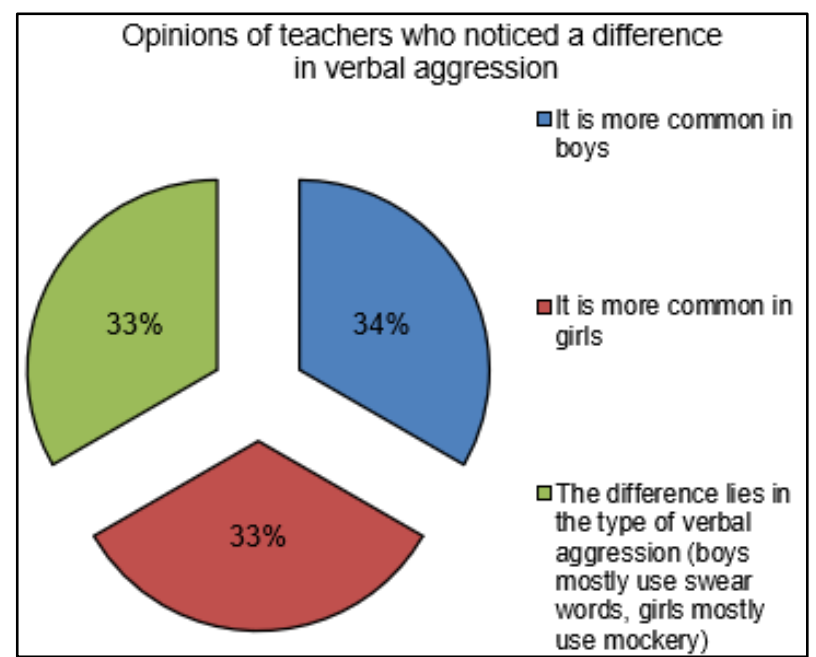

Figure 17. Opinions of teachers who noticed a difference in verbal aggression

Some indicative answers are those of participants N2: «I think that boys are somewhat superior here», N5: «many girls will use physical characteristics to abuse someone verbally, such as 'you are fat'», and N6: «the boys use swear words that even I would be ashamed to use $[\ldots]$ the girls will say things too, but they will mostly characterize the other kids as this or that». Four participants reported no difference. Those participants' opinions are presented in the following figure:

\section{Opinions of teachers who noticed no difference in verbal aggression}

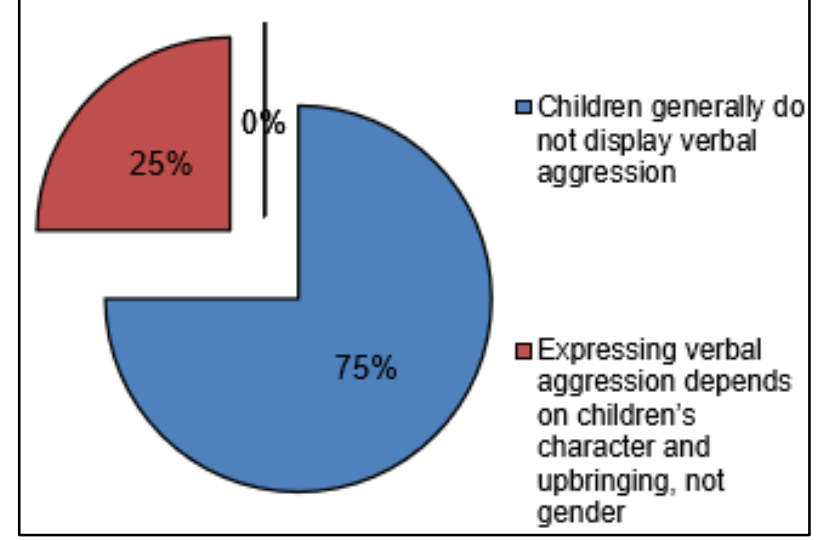

Figure 18. Opinions of teachers who did not notice a difference in verbal aggression 
Regarding relational aggression, eight participants reported a difference. Those participants' opinions are presented in the following figure:

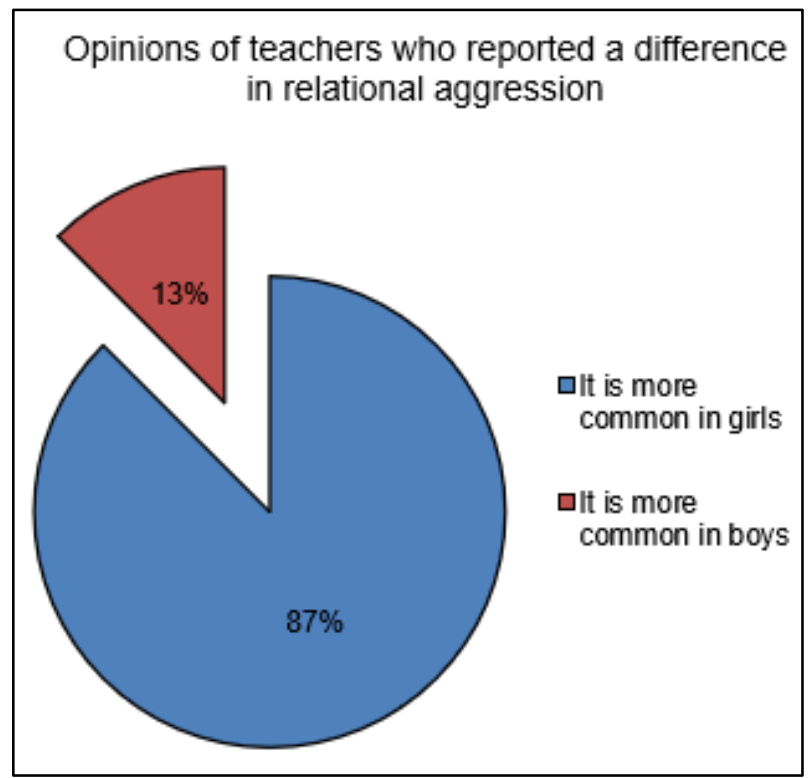

Figure 19. Opinions of teachers who noticed a difference in relational aggression

Some indicative answers are those of participants N1: «I think girls will hold more of a grudge» and N8: «boys will use phrases such as 'you are no longer my friend' a little easier than girls, but girls will usually discuss it later, after saying something like that». Two participants reported no difference, commenting that boys and girls show equal levels of relational aggression.

Regarding the case of gender-incompatible manifestation of aggressive behavior, five participants reported the same case: a girl who often showed physical aggression (e.g., N2: «there is a girl who is more spontaneous, she will hit more, she will be more competitive»). All five participants commented on the student's character or upbringing as a cause for such behavior (e.g., N4: «what we call a 'tomboy' exists in every class, they are those girls who are more independent and more dynamic»). Five participants reported no case.
Stances on gender stereotypes and managing related problems

The first question of this section was about the ways in which gender stereotypes affect kindergarten students. All participants agreed that gender stereotypes significantly affect students, commenting that the family plays a key role in transmitting gender stereotypes, in ways presented in the following figure:

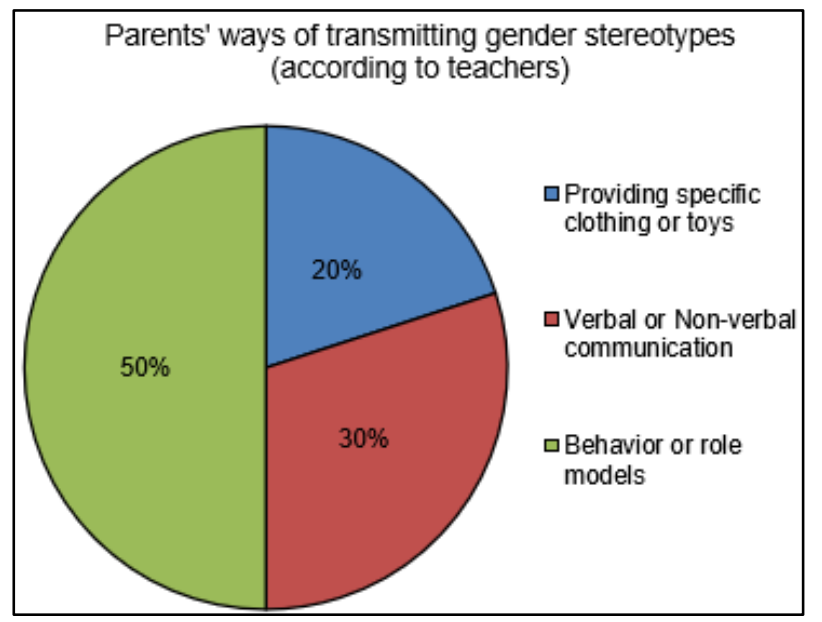

Figure 20. Ways in which parents transmit gender stereotypes to children, according to teachers

Two participants also reported that forms of entertainment (e.g., television) also transmit gender stereotypes and influence the image that students have of gender roles.

The second question was about the role of the kindergarten teacher in maintaining or combating gender stereotypes. All participants recognized the important role that teachers play, however three participants indicated that their influence does not exceed that of the family (e.g. N6: «his/her role is essential; she passes things on to her students $[\ldots]$ but it does not become a lifestyle change for the student if there is a family background that is not changed by the parents themselves»). The various practices reported for combating gender stereotypes are presented in the following figure: 


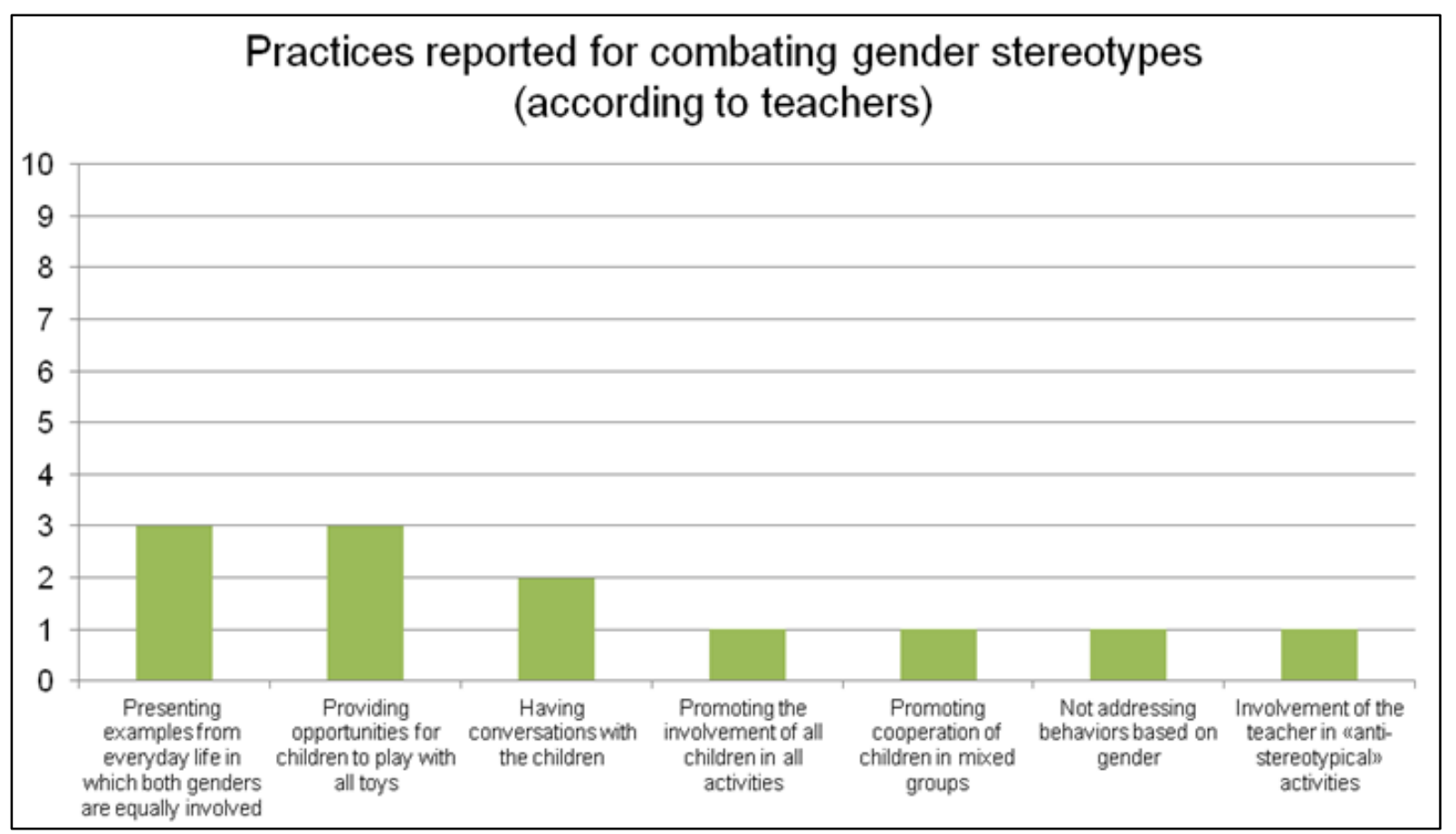

Figure 21. Practices for combating gender stereotypes at school, according to teachers

Two participants also mentioned that the kindergarten teacher could maintain gender stereotypes as well, if his/her beliefs agree with them, by separating the toys which are considered gender-appropriate or by using stereotypical speech when talking to the students (e.g., N9: «there are teachers who are very judgmental towards students and can even remove toys from their hands»).

The last two questions were about the existence of problems related to gender stereotypes in the class and the management of such problems. Nine participants reported a problem. Those participants' reports are presented in the following figure:

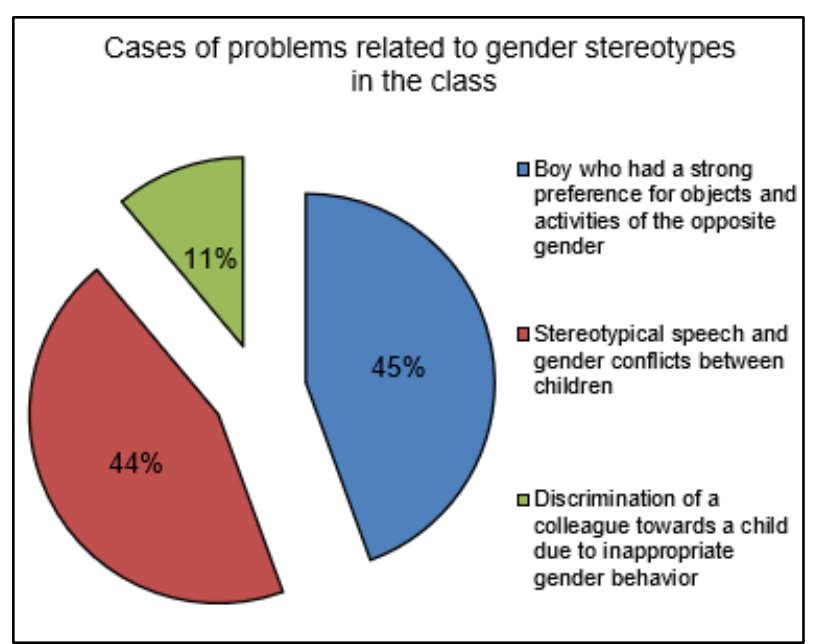

Figure 22. Teachers' experiences of problems related to gender stereotypes in the classroom

For problems related to an individual case of a student, the participants mentioned discussing with the parents as the main solution (e.g., N7: «I would like to talk to the parents, just to find out if they helped their child understand his or her gender. Not to change their behavior, nor to ask them for anything. After all, they are responsible for their child's behavior and upbringing, but just to see if they realized what was happening»). For problems related to relationships between students, participants mentioned discussing matters with the students themselves as the main solution (e.g., N8: «I solved it right then and there, by talking to the students, giving them a different point of view from the stereotypical one they had in their mind»). For a problem concerning the attitude of their colleagues, participant N9 mentioned discussing the problem with the school principal as the main solution. One participant did not report a case, commenting that the absence of such problems is due to the presence of a male kindergarten teacher at her school (e.g. N2: «the parents and students do not only see female kindergarten teachers, so some gender stereotypes are eradicated on their own because there is a male and a female role model at school»).

\section{Discussion of Data}

- What are the kindergarten teachers' perspectives on girls' and boys' choices of toys in the class?

Although various toys selected by students, on a daily basis, were reported, it was found that the predominant choices concerned toys that are considered stereotypical for each gender, such as dolls and kitchenware for girls or 
construction toys and vehicles for boys. A similar selection of toys by kindergarten girls and boys has been the object of numerous studies (see [27, 28]). Although several teachers in the present study commented that this choice was simply due to the student's preference for these toys, some reported that it was due to the innate inclination of boys and girls towards more inventive and quieter activities, respectively. This view is in line with the findings of Kogkidou [15], who states that adults tend to attribute stereotypical characteristics to the toys that each gender chooses, linking the need for providing care with "girl's" toys and the inclination to creativity with "boy's" toys. The kindergarten teachers who reported that they do not notice much difference in the choice of toys, between the two genders, noted that this was probably due to their classroom's system of rotating toys in the play corners. Through this system the toys are updated regularly, and mixed groups of students are defined in each corner, allowing students to explore all the toys. It seems, therefore, that the kindergarten teachers' practices regarding the availability and variety of class toys affect whether or not gender differences are maintained in this case. According to Lynch [29], it is very important for kindergarten teachers to consciously limit the stereotyping of certain toys and instead to encourage all students to experiment with various toys, as play is one of the key elements in building gender identity during young age.

- What are the kindergarten teachers' perspectives on girls' and boys' choices of games/outdoor activities at recess?

The comments of the kindergarten teachers in the present study showed that boys choose motor games more often during recess compared to girls. Studies on schoolyard play conducted by Holmes \& Procaccino [30] and Pawlowski et al. [31] had similar results, with boys engaging mainly in activities that require intense movement (e.g.: running) and girls choosing more static activities (e.g.: swings, symbolic play). In the present study, several kindergarten teachers described this difference as "normal" and attributed it to the innate characteristics of students, stating that boys are more energetic and active, while girls are gentler and more communicative. Similar characteristics related to students' physical activity can also be found in other studies (see [32]). Some kindergarten teachers also talked about rough-and-tumble play, which is a form of group play commonly observed amongst young students which involves intense (but not aggressive) physical contact, such as tickling, light slaps, or rolling on the ground [33]. Those kindergarten teachers reported that this is a game chosen almost exclusively by boys and is avoided by girls, which is consistent with the findings of numerous relevant studies (see [33]). Hence, it seems that girls' physical activity is lower than that of boys, at least during recess. Physical activity, however, often results from motor games which are played in the schoolyard and shows numerous physical, psychological, and social developmental benefits for students (see [34, 31]). It is, therefore, important to encourage the exposure of girls to such games and activities, in order for them to reap the benefits mentioned above, but also to familiarize them with new activities.

What are the kindergarten teachers' perspectives on girls' and boys' pro-social behavior at school?

A single conclusion regarding all forms of pro-social behavior (sharing, helping, cooperating, and defending) was not reached, as there was a difference of opinion amongst the kindergarten teachers, compared to the previous questions. The case of sharing was the only one in which there was unanimity about the absence of differences between genders, as several teachers explained that this behavior is based on a class rule that applies to all. It seems, therefore, that class rules help limit the different manifestations of sharing, which are in line with the views of Anderson \& Spaulding [35] and Burden [36] about the ways that rules benefit students, by reminding them of desirable behaviors and by offering structure and consistency. Regarding the other forms of pro-social behavior, differences were identified mainly in helping and defending, rather than cooperating. It was reported that girls are more willing to help than boys, due to their increased empathy, and that boys defend their friends in a more dynamic or aggressive manner, compared to girls. These views are consistent with the findings of Hastings et al. [20], who report that the pro-social behaviors of girls are manifested more as empathy and care, while those of boys as assertiveness and energy. It seems, therefore, that both boys and girls display pro-social behavior, but in a different way. More specifically, the differences in pro-social behavior between boys and girls depend on how that behavior is defined and measured [20]. Several kindergarten teachers, however, also reported cases of boys with great empathy, which was attributed to their upbringing or character. The same reasons were pointed out by the teachers who did not report any gender differences. These kindergarten teachers' beliefs are consistent with a number of studies regarding the influence of parenting practices on students' pro-social behavior (see [37]). In particular, parents who are warm, sensitive, and responsive towards their children set clear expectations for pro-social behavior, while parents who are very strict or punitive, but less emotional, provide a similar behavior model for their children [37].

What are the kindergarten teachers' perspectives on girls' and boys' aggressive behavior at school?

Regarding the forms of aggressive behavior examined (physical, verbal, and relational), clearer conclusions were drawn for the first and third form. The majority of the kindergarten teachers reported that physical aggression is 
more common in boys (8 out of the 10 kindergarten teachers), while relational aggression is more common in girls (7 out of the 10 kindergarten teachers). This specific difference in aggression between genders has been established by numerous related studies (see [21, 38]). The kindergarten teachers did not elaborate on whether this difference arises from students' inherent characteristics or from different parenting practices, however several researchers conclude in the latter case (see [39]). The different pedagogical approaches applied to boys and girls correspond to the different gender roles that students are considered to take on in later life. That is, the emphasis on girls' empathy and boys' determination aims to prepare students for the roles of the loving caregiver and the successful worker respectively [39]. Combined with this fact, Archer [22] states that parents are more tolerant of boys' aggressive tendencies but also that they themselves use corporal punishment more often as a means of controlling boys. It can therefore be concluded that, as girls are subjected to verbal or other form of discipline, they realize that they too need to express their anger or aggressive tendencies by using non-physical but more indirect ways, such as relational aggression. However, several kindergarten teachers also reported cases of girls who expressed severe physical aggression. That is part of a research that has not yet been studied extensively, which results in the effects of physical aggression on the emotional and social development of girls [21]. The cause of the aggression, however, can once again be attributed to the family. Cases of parents who adopt non-stereotypical roles and encourage girls' assertiveness more, but also cases of parents who directly or indirectly expose girls to physical violence, lead to the appearance of similar characteristics from girls in school [39].

\section{- How do kindergarten teachers evaluate the influence of gender stereotypes on students?}

It was found that all kindergarten teachers recognize the influence that gender stereotypes have on students, highlighting the important role of the family. The fact that early family experiences determine the adoption or rejection of gender stereotypes by students has been pointed out by many researchers (see [40-42]). The kindergarten teachers in the present study referred to the gender role models projected by the parents, the verbal or non-verbal messages, but also the provision of different clothes or toys, as determining factors. Research has shown that the practices mentioned above actually transmit gender stereotypes to students (see [41, 42]), as well as that parents' opinions on gender influence their interactions with boys and girls (see [40]). The role of teachers, through their attitude and communication with their students, was also deemed as important by the kindergarten teachers. The contribution of teachers to the transmission of gender stereotypes has been established by several studies (see [43]), however with the use of appropriate practices the opposite result can also be achieved. Presenting activities and occupations where both genders are equally involved, encouraging students to try a variety of activities, and having open discussions on gender issues are some of the practices that kindergarten teachers, cited in this study, apply as a means of combating gender stereotypes in the class. Similar practices have been shown to promote the anti-stereotyping ambiance in the class by other researchers (see [44, 45]). It can therefore be concluded that, through the cooperation and joint awareness of parents and teachers on gender stereotypes, it will be easier to promote a unanimous message of equality to students.

\section{- How do kindergarten teachers manage problems related to gender stereotypes in their class?}

It was found that the most common cases of problems encountered by kindergarten teachers were cases of a boy with a strong preference for "girly" objects and activities or cases of stereotypical speech and conflicts between students. The first case concerns students with gender-variant behavior, which differs from the stereotypical characteristics of their gender [46]. Although several researchers have noted that boys are more discouraged from their environment when they present "girlish" interests or behaviors (see [2, 47]), in the present study it can be seen that many boys feel comfortable by expressing an alternative gender behavior. The kindergarten teachers did not mention the discouragement of the students as a means of managing this issue, but the discussion they had with the parents, so that they have an idea of their child's situation at school. It seems, therefore, that these teachers' pay more attention to the students' right to free expression. This practice is also reported as positive by the research of Riley et al. [48], who pointed out that students with alternative gender behavior need respect, acceptance and support in order to express their identity. The second case of a problem concerns the stereotypical comments between students or the refusal of cooperation between them due to gender differences. As a variety of studies have shown, peer interactions play an important role in learning gender-appropriate behaviors in kindergarten (see [49]). It can therefore be concluded that, as students are usually exposed to typical gender behaviors, their expectations are shaped accordingly. Therefore, when they observe other students behaviors which do not meet these expectations, their image of gender is disturbed and they try to manage this confusion in any way they can. The kindergarten teachers' observations in the present study are consistent with the findings of Brown \& Stone [47], who report that students often react by discouraging, mocking, or rejecting peers who do not live up to specific gender expectations. Refusal of cooperation with classmates of the opposite 
gender is related to the tendency of students to show more positive attitudes towards people of the same gender from a very young age, as numerous studies have shown (see [50]). This fact, combined with the emphasis that stereotypes place on the differences between genders [47], justifies the negative predisposition that some students may have towards classmates of the opposite gender. Further establishment of stereotypes in the school context can intensify this predisposition and disrupt the class climate, therefore the intervention of the teacher is of great importance. The kindergarten teachers, in the present study, mentioned discussing with their students matters concerning gender stereotypes as a solution to this problem. This is another way of promoting equality in the class, as highlighted by the research of Giraldo \& Colyar [51], because the overthrow of gender stereotypes by kindergarten teachers, both in words and in deeds, gradually encourages students to perceive kindergarten as a framework where stereotypes that apply elsewhere do not apply there. The only kindergarten teacher in the present study who did not encounter a problem related to gender stereotypes stated that the very presence of a male kindergarten teacher in her school overthrows these stereotypes. Even today, pre-school and kindergarten education are considered a female-dominated space in many societies, a fact that is perceived by students and leads to stereotypes on gender roles [52]. The experience of this particular kindergarten teacher is confirmed by the findings of Cameron [53], who states that the presence of male teachers at a pre-school level is very important, as it brings equality and balance to the teaching staff but it also promotes an alternative "male" role to students.

\section{Conclusions}

The aim of this study was to explore kindergarten teachers' views on the presence of gender stereotypes in play (toys and games/activities) and students' behavior (pro-social and aggressive), as well as the teachers' attitudes concerning the influence of gender stereotypes on students of that age group. All of the initial research questions were answered satisfactorily in the previous section.

Regarding the toys, it was found that the dominant choices of students are toys that are stereotypically related to their gender, so differences were identified between boys and girls. Most kindergarten teachers were not surprised by these differences, attributing them to the students' preferences for these toys. Some kindergarten teachers, however, commented that the choices of specific toys are related to the inherent characteristics of boys or girls, a view that in itself is a gender stereotype.

Regarding games/activities, the differences in the level of mobility and physical activities between boys and girls became quite obvious, a fact that was again attributed by several kindergarten teachers to the innate different characteristics and 'inclinations' of their students.

Regarding the manifestation of pro-social behaviors, it was found that girls show behaviors that are based on empathy (e.g.: helping others) more intensely, while boys show behaviors that are based on capacity (e.g.: defending others) more intensely. As teaching pro-social behaviors is a key part of raising children, it seems that gender stereotypes influence the messages that adults convey to them about gender-appropriate behaviors, thus determining the pro-social behavior that children / students will display.

Regarding the manifestation of aggressive behaviors, it was found that girls show indirect forms of aggression (e.g.: relational aggression) more intensely, while boys show direct forms of aggression (e.g.: physical aggression) more intensely. It seems, therefore, that gender stereotypes determine students' aggressive behavior, forcing them to adapt the manifestation of their aggressive tendencies to the stereotypical characteristics usually attributed to them (e.g.: being gentle and kind for girls, being bold and capable for boys). In other words, gender stereotypes (which come from the home, the school, the television, etc.) which are internalized by students, force them to adjust their aggressive tendencies to fit these stereotypes. Indicatively, the stereotype that describes girls as sweet and calm forces girls to show mainly relational aggression, i.e., a more "calm" or a more indirect response to a situation. Respectively, the stereotype that describes boys as dynamic and energetic forces them to manifest mainly physical violence, which is more active but also more immediately apparent when it occurs.

Regarding the kindergarten teachers' evaluation of the influence that gender stereotypes have on their students, it was found that all kindergarten teachers were aware of its importance, pointing out the primary role played by the family and the important role of the teachers. It seems, therefore, that kindergarten teachers are informed about ways of combating gender stereotypes in kindergarten, as they mentioned various relevant practices; however, it is not clear whether they apply these practices on a permanent basis in their classes.

Finally, regarding the management of problems which related to gender stereotypes, it was found that kindergarten teachers consider talking to the parents or with the students themselves, as the most reliable solution to address each problem that may arise in their class. It seems, therefore, that kindergarten teachers emphasize on the cultivation of a communicative school climate with both students and their families, a practice that contributes to a mutual understanding and cooperation in the management of any problem that may arise.

In conclusion, it becomes clear that gender stereotypes, which are passed on consciously or unconsciously from one generation to another, have a significant impact on the 
process of students' socialization concerning gender. Once internalized by students, gender stereotypes can guide the course of their entire lives, from the choice of toys or activities to the choice of post school studies and employment prospects [54]. Although efforts have recently been made to promote gender equality, and although in many parts of the world men and women have access to the same rights and opportunities, differences in aspirations, motivations, participation and recognition in various areas of their lives is still felt [43]. Even though, the family primarily exerts an influence on their children, the role of the school is equally important in continuing or breaking the cycle of gender stereotypes [55]. Teachers, especially in preschool education, determine students' perceptions of gender, through the stimuli they provide and the way they treat their students. Raising the awareness of kindergarten teachers on this issue is therefore crucial. The decoration of the classroom with neutral materials, the supply of toys and books where various roles are represented, as well as the construction of a daily program that promotes the equal value and participation of both genders in different areas of life, are considered methods that contribute to creating an anti-stereotypical climate in the class. Through the use of similar methods and through the conscious attitude of teachers, more supportive learning environments can be built, where acceptance and respect for diversity prevail. These environments should convey the message that students should not allow their gender to stand in the way of their exploring other interests, activities, and roles [56].

\section{Limitations}

The main limitation of the present research study has to do with the small number of the sample, which does not allow the generalization of the results and for conclusions to be drawn which will include the whole population of Greek kindergarten teachers. It is also worth noting that, due to the COVID19 virus outbreak which took place during the research period, the interviews had to be conducted remotely, via video calls which were recorded. This method was considered the most appropriate for conducting the interviews because it reduced social contacts and thus the spread of the virus.

\section{Suggestions for Future Research}

In order to enhance the credibility of the conclusions drawn from the present study, it would be appropriate to conduct more research on the topic of gender stereotypes in kindergarten, with larger numbers of participants and by using different research methods. Indicatively, additional research could be conducted by distributing questionnaires to kindergarten teachers across Greece. A complementary research could also combine observation of students in the class with interviews from parents and kindergarten teachers, aiming at cross-referencing and at providing an in-depth study of the ways in which gender stereotypes affect students. Concerning the choice of toys and games/outdoor activities, a research could be conducted which could include interviews with girls and boys who attend kindergarten and who will speak for themselves about the toys and games/outdoor activities which they prefer to choose in kindergarten. Observation could also be conducted by their kindergarten teachers as to the actual choices of toys and games/outdoor activities which the aforementioned students actually choose when they play, in order to explore the similarities or differences between the girls' and the boys' choices in a more immediate context. Finally, as gender stereotypes in schools apply equally to male and female teachers, it would be particularly interesting to conduct additional research in order to explore the views of both female and male kindergarten teachers on this issue and to determine whether their perspectives converge or deviate from each other. The aforementioned proposals for further research in this area have, as their ultimate goal, the emergence of the issue of gender stereotypes in education, as a significant problem that deserves attention and treatment by schools, not only in Greece but at a global level.

\section{Acknowledgements}

We are very grateful to the kindergarten teachers who participated in this research. The authors of this research paper would like to thank them warmly for their contribution and their insightful remarks.

\section{REFERENCES}

[1] V. Pliogou, E. Kantartzi, M. Triantafyllou, “Gender representations in Science direction school textbooks in Class 5th and 6th of Primary school,” Journal of Research in Education, vol. 6, n. 1, pp. 140-160, 2017, Available online at: https://ejournals.epublishing.ekt.gr/index.php/hjre/article /view/11940. Also, see at: V., Teliousi, M. Zafiri,V. Pliogou, "Occupation and gender stereotypes in Primary School: The case of the English Language Coursebooks in Greek Primary Schools," Universal Journal of Educational Research, vol. 8, n. 4, pp. 1135-1148, 2020, Available online at: http://www.hrpub.org/download/20200330/UJER3-195146 29.pdf.

[2] O. Aina, P. Cameron, "Why Does Gender Matter? Counteracting Stereotypes With Young Children," Dimensions of Early Childhood, vol. 39, n. 3, pp. 11-20, 2011, Available online at: http://www.destinyearlychildhoo d.org/wp-content/uploads/2014/12/Why-Does-Gender-Matt er-Counteracting-Stereotypes-With-Young-Children.pdf.

[3] Ch. Gonitsioti, K. Magos, “A Car For Boys, A Doll For Girls? 
Exploring Kindergarten Teachers' Perceptions of Play-Object in Kindergarten,” Exploring the Child's World, vol. 15, pp. 11-21, 2016, Available online at: https://ejournals.epublishing.ekt.gr/index.php/omep/article/ view/22185.

[4] P. Goble, C. Martin, L. Hanish, R. Fabes, "Children's gender-typed activity choices across preschool social contexts,” Sex Roles, vol. 67, n. 7-8, pp. 435-451, 2012, Available online at: https://link.springer.com/article/10.100 7/s11199-012-0176-9

[5] M. Hughes, C. Kroehler, Sociology: The Basic Concepts, Athens, Review, 2014.

[6] E. Maragoudaki, Education and Gender Discrimination: Children's readings in kindergarten, Athens, Odysseus, 2005.

[7] L. Liben, R. Bigler, D. Ruble, C. Martin, K. Powlishta, “The developmental course of gender differentiation: Conceptualizing, measuring, and evaluating constructs and pathways," Monofigures of the society for research in child development, vol. 67, n. 2, pp. 1-185, 2002, Available online at: https://www.jstor.org/stable/pdf/3181530.pdf?refreqid=e xcelsior\%3Aa02e13879f876aacf222a8ce46a0e2d7.

[8] I. Kotronidou, "Pedagogical practices and gender identities in Kindergarten," 6th Panhellenic Conference of the Hellenic Institute of Applied Pedagogy and Education, Athens, October 5-7, 2012, Available online at: http://www.elliepek.gr/documents/6o_synedrio_eisigiseis/6 6_kotronidou_iwanna.pdf.

[9] A. Karathanasi-Katsaounou, "The role of the family environment in the formation of interracial relationships", in Interracial relations: Presentations at the Teacher Training Seminar-Issues of Sex Education and Gender Equality, Athens, Greek Letters, 1998.

[10] L. Brannon, Gender: Psychological perspectives, Boston, Pearson, 2011.

[11] L. Frosi, V. Deligianni-Kuimtzi, "Opinions and expectations of teachers for boys and girls in school”, in Teachers and gender, Athens, K.E.TH.I., 2008, Available online at: https://www.kethi.gr/sites/default/files/wp-content/uploads/ 2009/01/146_6_EKPAIDEYTIKOI_FYLO.pdf

[12] T. Riley, "Boys are like puppies, girls aim to please: How teachers' gender stereotypes may influence student placement decisions and classroom teaching," Alberta Journal of Educational Research, vol. 60, n. 1, pp. 1-21, 2014, Available online at: https://cdm.ucalgary.ca/index.php/ajer/ article/view/55729.

[13] C. Gosselin, "Philosophy and the Role of Teacher Reflections on Constructing Gender," Educational Foundations, vol. 21, n.3-4, pp. 39-57, 2007, Available online at: https://eric.ed.gov/?id=EJ831201.

[14] K. Wohlwend, “«Are you guys girls?»: Boys, identity texts, and Disney princess play,” Journal of Early Childhood Literacy, vol. 12, n. 1, pp. 3-23. 2011, Available online at: https://journals.sagepub.com/doi/abs/10.1177/14687984114 16787.

[15] D. Kogkidou, Beyond pink and light blue: All toys for all children, Athens, Epikendro, 2015.

[16] M. Tsigra, Inside the Kindergarten: Procedures and practices of constructing everyday reality, Athens, Lexitipon, 2014.

[17] R. Holmes, J. Procaccino, "Preschool children's outdoor play area preferences,” Early Child Development and Care, vol. 179, n. 8, pp. 1103-1112, 2009, Available online at: https://www.tandfonline.com/doi/abs/10.1080/0300443070 1770694.

[18] R. Storli, "Characteristics of indoor rough-and-tumble play (R\&T) with physical contact between players in preschool," Nordic Early Childhood Education Research Journal, vol. 6, n. 16, pp. 1-15, 2013, Available online at: https://journals.hioa.no/index.php/nbf/article/view/342.

[19] K. Van Leeuwen, T. Meerschaert, G. Bosmans, L. De Medts, C. Braet, "The Strengths and Difficulties Questionnaire in a community sample of young children in Flanders," European Journal of Psychological Assessment, vol. 22, n. 3, pp. 189-197, 2006, Available online at: https://econtent.hog refe.com/doi/abs/10.1027/1015-5759.22.3.189.

[20] P. Hastings, K. McShane, R. Parker, F. Ladha, "Ready to Make Nice: Parental Socialization of Young Sons' and Daughters' Prosocial Behaviors With Peers”, The Journal of Genetic Psychology: Research and Theory on Human Development, vol. 168, n. 2, pp. 177-200, 2007, Available online at: https://www.tandfonline.com/doi/abs/10.3200/G NTP.168.2.177-200.

[21] M. Zimmer-Gembeck, T. Geiger, N. Crick, "Relational and physical aggression, prosocial behavior, and peer relations: Gender moderation and bidirectional associations," The Journal of Early Adolescence, vol. 25, n. 4, pp. 421-452, 2005, Available online at: https://journals.sagepub.com/doi/ abs/10.1177/0272431605279841.

[22] J. Archer, "Sex differences in aggression in real world settings: A meta-analytic review," Review of General Psychology, vol. 8, n. 4, pp. 291-322, 2004, Available online at: https://journals.sagepub.com/doi/abs/10.1037/108 9-2680.8.4.291.

[23] J. Ostrov, N. Crick, C. Keating, “Gender-biased perceptions of preschoolers' behavior: how much is aggression and prosocial behavior in the eye of the beholder?," Sex roles, vol. 52, n. 5-6, pp. 393-398, 2005, Available online at: https://link.springer.com/article/10.1007/s11199-005-26816.

[24] J. Creswell, J. Creswell, Research design: Qualitative, quantitative, and mixed methods approaches, $4^{\text {th }}$ ed., London, Sage publications, 2014.

[25] C. Kölbl, "Qualitative Approaches in the Research of Historical Learning”, in Empirical Research on History Learning, Yearbook 2010, Frankfurt, Wochenschau Verlag, 2010.

[26] K. Krippendorf, Content Analysis: An Introduction to Its Methodology, New York, SAGE, 2004.

[27] E. Wood, S. Desmarais, S. Gugula, “The impact of parenting experience on gender stereotyped toy play of children," Sex Roles, vol. 47, n. 1-2, pp. 39-49, 2002, Available online at: https://link.springer.com/article/10.1023/A:1020679619728

[28] I. Cherney, K. London, "Gender-linked differences in the toys, television shows, computer games, and outdoor activities of 5- to 13-year-old children," Sex Roles, vol. 54, n. 9-10, pp. 717-726, 2006, Available online at: 
https://link.springer.com/article/10.1007/s11199-006-90378

[29] M. Lynch, “Guys and dolls: A qualitative study of teachers' views of gendered play in kindergarten," Early Child Development and Care, vol. 185, n. 5, pp. 679-693, 2015, Available online at: https://www.tandfonline.com/doi/abs/1 $0.1080 / 03004430.2014 .950260$.

[30] R. Holmes, J. Procaccino, "Preschool children’s outdoor play area preferences,” Early Child Development and Care, vol. 179, n. 8, pp. 1103-1112, 2009, Available online at: https://www.tandfonline.com/doi/abs/10.1080/0300443070 1770694.

[31] C. Pawlowski, C. Ergler, T. Tjørnhøj-Thomsen, J. Schipperijn, J. Troelsen, “«Like a soccer camp for boys»: A qualitative exploration of gendered activity patterns in children's self-organized play during school recess," European Physical Education Review, vol. 21, n. 3, pp. 275-291, 2014, Available online at: https://journals.sagepub .com/doi/abs/10.1177/1356336x14561533.

[32] E. Zachopoulou, E. Trevlas, G. Tsikriki, "Perceptions of gender differences in playful behaviour among kindergarten children,” European Early Childhood Education Research Journal, vol. 12, n. 1, pp. 43-53, 2004, Available online at: https://www.tandfonline.com/doi/abs/10.1080/1350293048 5209301.

[33] G. Koustourakis, C. Rompola, A. Asimaki, "Rough and tumble play and gender in kindergarten: Perceptions of kindergarten teachers,” International Research in Education, vol. 3, n. 2, pp. 93-109, 2015, Available online at: http://www.macrothink.org/journal/index.php/ire/article/vi ew/7570/6407

[34] R. Holmes, "The Outdoor Recess Activities of Children at an Urban School: Longitudinal and Intraperiod Patterns," American Journal of Play, vol. 4, n. 3, pp. 327-351, 2012, Available online at: https://eric.ed.gov/?id=EJ985597.

[35] C. Anderson, S. Spaulding, "Using Positive Behavior Support to Design Effective Classrooms,” Beyond Behavior, vol. 16, n. 2, pp. 27-31, 2007, Available online at: https://eric.ed.gov/?id=EJ840247.

[36] P. Burden, Classroom management: Creating a Successful K-12 Learning Community, $7^{\text {th }}$ ed., New Jersey, John Wiley \& Sons, 2020.

[37] P. Hastings, K. Rubin, L. DeRose, "Links among gender, inhibition, and parental socialization in the development of prosocial behavior,” Merrill-Palmer Quarterly, vol. 51, n. 4, pp. 467-493, 2005, Available online at: https://www.jstor.org/stable/pdf/23096098.pdf?refreqid=ex celsior\%3A6b5fc2547a72e451be637449f61bf113.

[38] A. Eivers, M. Brendgen, A. Borge, "Stability and change in prosocial and antisocial behavior across the transition to school: Teacher and peer perspectives,” Early Education and Development, vol. 21, n. 6, pp. 843-864, 2010, Available online at: https://www.tandfonline.com/doi/abs/10.1080/10 409280903390684.

[39] J. Endendijk, M. Groeneveld, L. Van der Pol, S. Van Berkel, E. Hallers-Haalboom, M. Bakermans-Kranenburg, J. Mesman, "Gender differences in child aggression: Relations with gender-differentiated parenting and parents' gender-role stereotypes,” Child development, vol. 88, n. 1, pp. 299-316, 2017, Available online at: https://srcd.onlineli brary.wiley.com/doi/abs/10.1111/cdev.12589.

[40] J. Endendijk, M. Groeneveld, S. Van Berkel, E. Hallers-Haalboom, J. Mesman, M. Bakermans-Kranenburg, "Gender stereotypes in the family context: Mothers, fathers, and siblings," Sex roles, vol. 68, n. 9, pp. 577-590, 2013, Available online at: https://link.springer.com/article/10.100 7\%252Fs11199-013-0265-4.

[41] J. Endendijk, M. Groeneveld, L. Van der Pol, S. Van Berkel, E. Hallers-Haalboom, J. Mesman, M. Bakermans-Kranenburg, "Boys don't play with dolls: Mothers' and fathers' gender talk during picture book reading," Parenting, vol. 14, n. 3-4, pp. 141-161, 2014, Available online at: https://www.tandfonline.com/doi/abs/1 0.1080/15295192.2014.972753.

[42] V. Morrow, "Understanding gender differences in context: implications for young children's everyday lives," Children \& society, vol. 20, n. 2, pp. 92-104, 2006, Available online at: https://onlinelibrary.wiley.com/doi/abs/10.1111/j.1099-086 0.2006.00017.x.

[43] B. Segatto, A. Dal Ben, "Gender and Affectivity Awareness in Kindergarten: An Educational Pathway for Boys, Girls and Their Teachers," Italian Journal of Sociology of Education, vol. 11, n. 1, pp. 184-204, 2019, Available online at: https://ijse.padovauniversitypress.it/2019/1/9.

[44] B. Aksu, "Barbie against superman: Gender stereotypes and gender equity in the classroom,” Journal of Language and Linguistic studies, vol. 1, n. 1, pp. 12-21, 2005, Available online at: http://jlls.org/index.php/jlls/article/view/2.

[45] G. Timmerman, P. Schreuder, "Pedagogical professionalism and gender in daycare,” Gender and Education, vol. 20, n. 1, pp. 1-14, 2008, Available online at: https://www.tandfonlin e.com/doi/abs/10.1080/09540250701763301.

[46] G. Slesaransky-Poe, A. García, "Boys with gender variant behaviors and interests: From theory to practice," Sex Education, vol. 9, n. 2, pp. 201-210, 2009, Available online at: https://www.tandfonline.com/doi/abs/10.1080/14681810 902829679 .

[47] C. Brown, E. Stone, “Gender stereotypes and discrimination: How sexism impacts development," Advances in child development and behavior, vol. 50, pp. 105-133, 2016, Available online at:https://www.sciencedirect.com/science/ article/pii/S0065240715000348.

[48] E. Riley, G. Sitharthan, L. Clemson, M. Diamond, "The needs of gender-variant children and their parents: A parent survey,” International Journal of Sexual Health, vol. 23, n. 3, pp. 181-195, 2011, Available online at: https://www.tandfo nline.com/doi/abs/10.1080/19317611.2011.593932.

[49] E. Baker, M. Tisak, J. Tisak, "What can boys and girls do? Preschoolers' perspectives regarding gender roles across domains of behavior," Social Psychology of Education, vol. 19, n. 1, pp. 23-39, 2016, Available online at: https://link.sp ringer.com/article/10.1007/s11218-015-9320-z.

[50] D. Abrams, A. Rutland, L. Cameron, J. Marques, "The development of subjective group dynamics: When in-group bias gets specific," British Journal of Developmental Psychology, vol. 21, n. 2, pp. 155-176, 2003, Available online at: https://onlinelibrary.wiley.com/doi/abs/10.1348/0 26151003765264020. 
[51] E. Giraldo, J. Colyar, "Dealing with gender in the classroom: A portrayed case study of four teachers," International Journal of Inclusive Education, vol. 16, n. 1, pp. 25-38, 2012, Available online at: https://www.tandfonline.com/doi/abs/1 0.1080/13603110903518216.

[52] D. Piburn, B. Nelson, F. Carlson, "Men in teaching: Gender equality through the promise of gender balance," YC Young Children, vol. 66, n. 5, pp. 64-66, 2011, Available online at: https://search.proquest.com/openview/33a34a6502ff8296aa bd0668ee5729be/1?pq-origsite=gscholar\&cbl=27755.

[53] C. Cameron, "Promise or problem? A review of the literature on men working in early childhood services," Gender, Work \& Organization, vol. 8, n. 4, pp. 430-453, 2001, Available online at: https://onlinelibrary.wiley.com/doi/abs/10.1111/1 468-0432.00140.
[54] K. Mulvey, M. Killen, "Challenging gender stereotypes: Resistance and exclusion,” Child Development, vol. 86, n. 3, pp. 681-694, 2015, Available online at: https://srcd.onlineli brary.wiley.com/doi/abs/10.1111/cdev.12317.

[55] M. Kollmayer, B. Schober, C. Spiel, "Gender stereotypes in education: Development, consequences and intervantions," European Journal of Developmental Psychology, vol. 15, n. 4, pp. 361-37, 2016, Available online at: https://www.tandf online.com/doi/abs/10.1080/17405629.2016.1193483.

[56] D. Ehrensaft, "From gender identity disorder to gender identity creativity: True gender self child therapy,” Journal of homosexuality, vol. 59, n. 3, pp. 337-356, 2012, Available online at: https://www.tandfonline.com/doi/abs/10.1080/00 918369.2012.653303. 